\title{
PROPOSTA DE IMPLEMENTAÇÃO SISTEMA DE BONIFICAÇÃO NO GRUPO MILLENIUM SEGURANÇA PATRIMONIAL
}

\section{ARTIGO ORIGINAL}

SANTOS, Sjoberg Wilke Oliveira dos 1, MAQUINÉ, Mauro Noronha 2, LIMA, Francisco Yury Minguim ${ }^{3}$, ROBERTO, José Carlos Alves ${ }^{4}$

SANTOS, Sjoberg Wilke Oliveira dos. Et al. Proposta de implementação sistema de bonificação no Grupo Millenium Segurança Patrimonial. Revista Científica Multidisciplinar Núcleo do Conhecimento. Ano 06, Ed. 05, Vol. 07, pp. 158-183. Maio de 2021. ISSN: 2448-0959, Link de acesso:

https://www.nucleodoconhecimento.com.br/administracao/grupo-millenium, DOI: 10.32749/nucleodoconhecimento.com.br/administracao/grupo-millenium

\section{RESUMO}

As empresas estão vivenciando um ambiente, em que constantemente deparam-se com novos desafios, tecnologias, leis e modelos de gestão, é um mercado cada vez mais competitivo, consequentemente exige das empresas a superação desses desafios, a fim de se tornarem eficientes e eficazes. Dentro de uma organização a gestão se torna importantíssima com intuito obter um crescimento do lucro da empresa é necessário manter seus colaboradores motivados realizando um

${ }^{1}$ Graduando do curso de Administração.

${ }^{2}$ Graduando do curso de Administração.

${ }^{3}$ Graduando do curso de Administração.

${ }^{4}$ Orientador. Mestrado profissional em Engenharia de produção. Especialização em Gestão em Logística empresarial. Graduação em Administração com Ênfase em Marketing.

RC: 84992

Disponível em: https://www.nucleodoconhecimento.com.br/administracao/grupo-millenium 
gerenciamento de pessoas correto faz com que diminua o tempo para realização de tarefas, tempo ocioso por partes dos trabalhadores, e por consequência um grande aumento na produtividade. Porém, essa não é a única perspectiva relevante para essa pesquisa, ela justifica também pelo fato de haver a necessidade de enfatizar que esse tipo de organização deva preocupar-se com o seu principal recurso, o recurso humano, e não o tratar como um mero recurso. O presente artigo tem por objetivo descrever quais as práticas de devem ser empregadas para manter seus colaboradores motivados, a fim de evidenciar os benefícios. O presente trabalho realizou uma pesquisa bibliográfica e posteriormente um estudo de caso com a empresa Millenium. Pode-se identificar pontos preponderantes que foram indispensáveis para o crescimento da empresa, observando os resultados pode-se elencar os tais fatores, destacando-se o emprego da valorização dos funcionários mais antigos na empresa, o incentivo que a empresa promove a seus colaboradores a se qualificarem criando dessa forma um plano de carreira, priorização dos colaboradores a ocupar novas vagas e a valorização dos profissionais mais empenhados.

Palavras-Chave: Gerenciamento de pessoas, Sistema de bonificação, Produtividade.

\section{INTRODUÇÃO}

Com o aumento dos concorrentes, novos segmentos de mercado e o aumento das exigências por parte dos consumidores, as empresas se veem obrigadas a criar estratégias para manterem-se competitivas em um ambiente cada vez mais desafiador e versátil.

Carvalho et al. (2017), afirma que o termo concorrência é entendido como, a junção de políticas e fatores que determinam o nível de prosperidade que a economia de um país pode alcançar, assim a concorrência depende também de fatores sociais,

RC: 84992

Disponível em: https://www.nucleodoconhecimento.com.br/administracao/grupo-millenium 
econômicos e do comportamento dos mercados, impulsionando o crescimento da manufatura, a fim de satisfazer os desejos e necessidades dos clientes.

As empresas estão vivenciando um ambiente em que se deparam constantemente com novos desafios, tecnologias, legislações e modelos de gestão, é um mercado cada vez mais competitivo, que acaba com as empresas que superam esses desafios para se tornarem mais rentáveis.

Dentro de uma organização a gestão de se torna importantíssima para o aumento da produtividade e sucesso da empresa, pois são indispensáveis nos processos produtivos, um gerenciamento de pessoas correto faz com que diminua o tempo para realização de tarefas, tempo ocioso por partes dos trabalhadores, e por consequência um grande aumento da motivação em uma empresa.

Porém, essa não é a única perspectiva relevante para essa pesquisa, ela justifica também pelo fato de haver a necessidade de enfatizar que esse tipo de organização deva preocupar-se com o seu principal recurso, o recurso humano, e não o tratar como um mero recurso, visto que depende desta mão-de-obra, e que esta, por sua vez, exerce um trabalho exaustivo fisicamente e merece atenção por parte das organizações. Pensando sob esta ótica, a fim de nortear esta pesquisa formulou-se a seguinte pergunta problema: Como a introdução de políticas motivacionais de bonificação pode contribuir com o aumento da produtividade dos colaboradores?

Todas as empresas têm um objetivo em comum, que guia todas as ações de seus dirigentes visando o lucro, que é uma consequência do aumento da produtividade. Para alcançarem isso, existem várias ferramentas usadas para se conseguir estes resultados, como por exemplo, a gestão de pessoas (SANTOS, 2018). reconhecimento pelo bom trabalho e o incentivo aos seus colaboradores é essencial para a eficiência da empresa, o que contribui para o sucesso dos projetos, e investimentos na área de conhecimento dando valor a sua força de trabalho.

RC: 84992

Disponível em: https://www.nucleodoconhecimento.com.br/administracao/grupo-millenium 
Assim, este artigo tem como objetivo caracterizar quais práticas devem ser empregadas para manter seus funcionários motivados para comprovar os benefícios que um sistema extra gera para a empresa e seus funcionários. O presente trabalho realizou a pesquisa bibliográfica e, a seguir, um determinado estudo de caso com a empresa MILLENIUM. Para a conclusão desta pesquisa, o método escolhido foi a busca bibliográfica, na qual a coleta de dados foi com dados de qualidade, em livros, artigos e pesquisas virtuais, para que fosse realizada a análise, identificando boas práticas dos funcionários.

\section{REVISÃO BIBLIOGRÁFICA}

\subsection{LIDERANÇA}

A liderança pode ser entendida como a arte de mobilizá-las em prol de um objetivo comum, para isso a líder precisa se perguntar: O que você precisa para seu pessoal de liderança ingressar em uma organização? O que é imprescindível para que as pessoas possam obter desempenho de alto nível? $\mathrm{O}$ que pode ser dado à lealdade das pessoas? Ciente de que existe uma diferença entre obter suporte e solicitar. Existe uma grande diferença entre boa gestão e liderança. A boa gestão concentrase na realização de certos objetivos por meio do desenvolvimento de planos e do desenho de estruturas organizacionais rígidas e dos resultados do rastreamento. Liderança significa influenciar um determinado grupo a atingir metas (FERNANDES, 2016).

A sociedade em geral possui como essencial a liderança para se alcançar bons resultados em várias áreas. O líder é o principal motivador da equipe, e ele estabelece essa fatores motivacionais, de acordo com cada componente em sua equipe (RAMOS, 2015). Um dos artifícios utilizados pelos líderes para manter o desempenho elevado de suas equipes é através de recompensas mediante a um

RC: 84992

Disponível em: https://www.nucleodoconhecimento.com.br/administracao/grupo-millenium 
bom desempenho utilizando como orientação para transações e que tem seus pilares meritocráticos (DIAS et al., 2015).

\subsection{TIPOS DE LIDERANÇA}

\subsubsection{LIDERANÇA AUTOCRÁTICA}

No modelo de liderança autocrática, o gestor determina tudo o que o grupo deve fazer, as diretrizes, a função de cada elemento, o método e o planejamento adotado. Nesse tipo de liderança, o líder personifica ou complementa, sejam eles críticos para cada elemento da organização. O chefe está no centro de todas as decisões tomadas e existe uma grande centralização de poder que não permite que outros interfiram. Uma das principais características da liderança autocrática está na coleta de resultados (GARCIA, 2015).

Enquanto o líder autocrático se concentra na tomada de decisões, o líder democrático permite que os membros de sua equipe possam opinar e auxiliar no planejamento. A liderança democrática é centrada na pessoa que faz o trabalho, e essa pessoa recebe maior controle e, portanto, maior liberdade e satisfação (CRUZ; PAIS; PARENTE, 2014).

\subsubsection{LIDERANÇA LIBERAL}

A liderança liberal permite a liberdade geral que sua equipe pode resistir ao líder. Nesse tipo de liderança dos membros da equipe, eles decidem a si mesmos, quais são as melhores medidas para resolver os problemas que podem ocorrer. Nesse tipo de liderança, a líder dura apenas algumas decisões, porque os outros membros das equipes dão distribuição elétrica, porque os outros membros da falta de eficiência dão grande liberdade (GARCIA, 2015).

RC: 84992

Disponível em: https://www.nucleodoconhecimento.com.br/administracao/grupo-millenium 


\subsubsection{LIDERANÇA SITUACIONAL}

A orientação situacional é aquela que adapta a situação que enfrenta, neste modelo líder, o líder pode facilmente se adaptar à situação conhecendo melhor para administrar sua equipe, esse tipo de liderança exige que este líder tenha a capacidade de avaliar os cenários e contextos. e, em particular, o nível de capacidade técnica, comportamental e emocional de seus profissionais, para atribuir suas tarefas corretamente e obter os resultados esperados (PEREIRA, 2014).

\subsection{A GESTÃO DE PESSOAS}

O gerenciamento de pessoas depende exclusivamente dos recursos humanos e das organizações para funcionar, cada um com seu objetivo. Enquanto as pessoas pensam em trabalhar para alcançar uma vida profissional melhor, a empresa objetiva o lucro, através do fornecimento de uma proposta de valor, que o cliente esteja disposto a pagar. Sobre essa correlação, Chiavenato (2014) deixa claro que as empresas não poderiam funcionar sem seu ativo mais precioso, as pessoas, visto que sem pessoas não há que realize trabalho e as pessoas sem trabalho não teriam como se manter financeiramente e essa dependência é que torna relevante esta pesquisa, como já comentado o setor de construção depende em alta escala dessa relação, sendo assim é plausível que se mostre quais as melhorias que a gestão de pessoas pode trazer para as organizações, logo para as pessoas que fazem parte dela, para que juntos elevem os seus níveis de sucesso.

A principal diferença entre recursos humanos e GP é em relação à rotina da organização. Os recursos humanos é uma ponte entre o relacionamento entre as empresas e o funcionário. A GP se ocupa no desenvolvimento de competências. Por isso é tão importante entender a diferença entre recursos humanos e gestão de pessoas. Que apesar de serem áreas que se complementam, por vezes desempenham papéis diferentes na organização. No caso dos recursos humanos

RC: 84992

Disponível em: https://www.nucleodoconhecimento.com.br/administracao/grupo-millenium 
preza em manter toda empresa funcionando, e a gestão de pessoas, mantém a equipe unida, focada e em harmonia (BIANCHI; QUISHIDA; FORONI, 2017).

A administração de recursos humanos, ou comumente conhecida $\mathrm{RH}$, pode ser comparada com a Abordagem Clássica da Administração, na qual não considera as pessoas, como pessoas, mas como meros recursos humanos, um mero empregado. É um recurso assim, como financeiro e material, que existe para a empresa funcionar.

Essa administração de recursos humanos tem sofrido alterações ao longo dos anos, e está comumente sendo chamada de Gestão de Pessoas, no qual agora enxerga a pessoa como ser humano, preocupando-se com o bem-estar, analisando esse indivíduo na organização.

Diante dessas afirmações, é necessário que empresas adotem uma Gestão de Pessoas, que dê valor ao capital humano nas organizações, e que passe a analisar seus funcionários, que eles possam exercer não somente sua função, mas que possa torná-lo um colaborador, que se alinhe e caminhe na mesma direção da empresa.

Com a adoção da gestão de pessoas, proporciona-se a criação da cultura organizacional, que vai ser responsável por difundir a missão, visão e valores da empresa para seus colaboradores, além de contribuir com as ações deste departamento para a produtividade, motivação e desempenho, assim como saber melhor lidar com as ações para processos seletivos, escolhendo os melhores colaboradores para sua empresa. Esses processos seletivos acontecem através do recrutamento e seleção de pessoas.

O recrutamento consiste na divulgação de uma oportunidade, onde tenta-se atrair os candidatos para o processo seletivo, consequentemente a empresa. A seleção de pessoas, como Chiavenato (2014) afirma "faz parte do processo de agregar pessoas RC: 84992

Disponível em: https://www.nucleodoconhecimento.com.br/administracao/grupo-millenium 
e funciona logo após o recrutamento. Ambos - recrutamento e seleção de pessoas fazem parte de um mesmo processo: a introdução de novos talentos na organização", logo esses processos ajudariam na escolha de futuros profissionais, o encarregado pelas ações de gestão de pessoas quando realizarem o processo seletivos deverão saber como guiar as atividades na hora da seleção, para que consiga identificar os valores que a empresa procura, ou seja se ele adequa-se a cultura organizacional, isso acontece no processo de integração na empresa, que é uma forma de mostrar como tudo acontece, para aquele novo funcionário, para que ele se sinta à vontade e parte do time.

Consequentemente, isso o ajudará a desempenhar suas funções de acordo com o que a empresa deseja, com qualidade de atendimento, satisfação, motivação e produtividade. Quando se fala no processo de seleção e recrutamento de pessoas, é importante salientar que estes dois fazem parte do primeiro processo básico da gestão de pessoas, processos esses que são divididos ainda em mais cinco processos, conforme a Figura 1 abaixo.

Figura 1- Os cinco processos básicos de gestão de pessoas

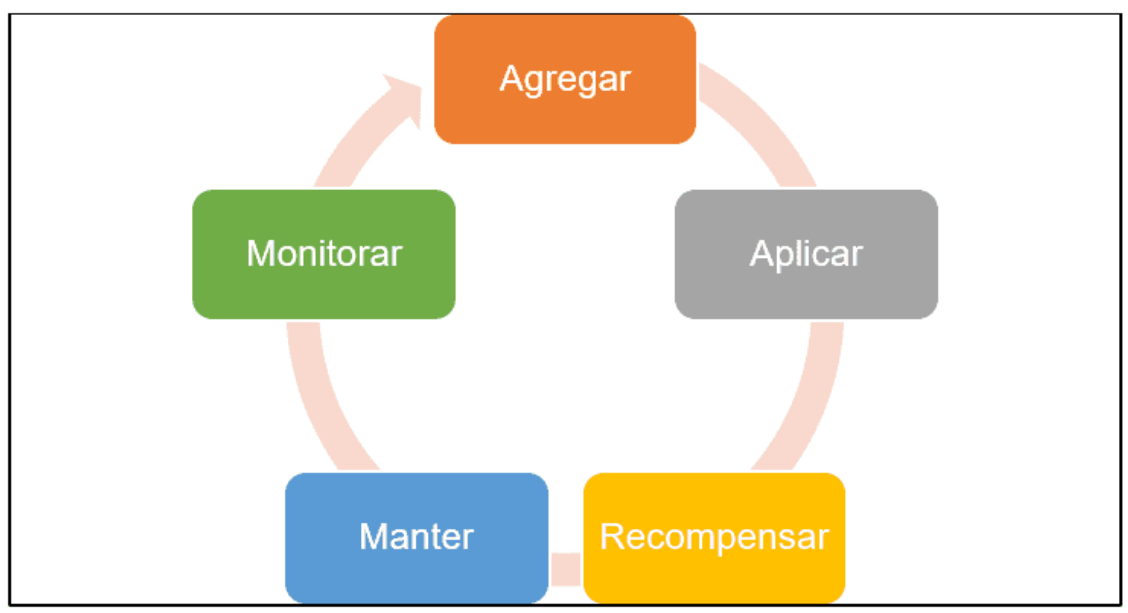

Fonte: Adaptado Silva (2018)

RC: 84992

Disponível em: https://www.nucleodoconhecimento.com.br/administracao/grupo-millenium 
Em relação ao processo de agregar pessoas, Silva (2018) afirma que o objetivo do procedimento para adicionar pessoas é separar características de cada indivíduo capazes para aquela função a fim de que a empresa forneça ao quadro funcionários qualificados e possa usar todo o seu conhecimento em suas respectivas funções e, portanto, desenvolver rapidamente. Contribuição para satisfazer as expectativas e expectativas atuais e futuras da organização. Nesse processo estão incluídos os processos de recrutamento e seleção que já foram abordados anteriormente. No processo de aplicar pessoas consiste no direcionamento das pessoas, uma vez contratadas, essas pessoas devem ser integradas a organização, e colocadas em seus respectivos cargos e tarefas (SILVA, 2018).

É vital que o funcionário receba as orientações claras sobre a empresa, para que facilite sua adequação. A avaliação de desempenho tem como finalidade aferir os resultados obtidos pelos seus colaboradores e medir a produtividade e também como ferramenta de para avaliar a contribuição que cada funcionário teve para alcançar o objetivo da empresa.

Quanto a recompensa de pessoas, em suma é como essas pessoas são remuneradas, incentivadas e ao mesmo tempo satisfeitas com suas expectativas. Essas expectativas geralmente resumem-se na forma de pagamento, na qual a troca pelo seu trabalho, nesse sentido uma característica importante é que o gestor deve saber identificar, que a remuneração não é somente um meio de incentivo, muitas vezes o reconhecimento do trabalhador, o faz sentir motivado e disposto a empenhar melhor suas necessidades (CHIAVENATO, 2014).

Esse ponto de vista, é bem útil para as empresas, visto que às vezes dependendo da atividade que a empresa realiza se torna um lugar extremamente difícil para socialização. Para se obter bom rendimento do trabalhador, outro processo a ser aplicado é o desenvolvimento de pessoas, através de treinamentos especializados 
para determinadas funções, integração social com todos da empresa, a fim de desenvolver novas atitudes, e como consequência gera a eficiência dessas pessoas.

No processo de monitoramento, é o momento em que podemos determinar a eficiência das pessoas, através do rendimento de seus trabalhos, de como estão sendo realizadas as suas atividades, e a condições a que seus empregados estão submetidos. Chiavenato (2014), afirma ainda que se incluem ainda podem ser inseridos diversos outros fatores como ambiente, cultura, qualidade de vida entre outros pontos que afetam diretamente seus resultados na organização. Por fim, é necessário que a equipe de gestão de pessoas tenha um controle de monitoramento de seus trabalhadores.

\subsection{GERENCIAMENTO ESTRATÉGICO DE PESSOAS}

O processo de gerenciamento de pessoas é feito pela busca, retenção, avaliação de desempenho e desenvolvimento da equipe. Este processo é a ligação entre os funcionários e a organização, que procura integrar estes dois elementos, como também tornar a relação entre eles harmoniosa e benéfica para ambas as partes. Como o sucesso está diretamente relacionado às pessoas que as compõem. $\mathrm{O}$ gestor de pessoas atua também como um filtro de profissionais capacitados e comprometido com a missão e objetivo da empresa, é a partir do gestor que isso acontece. Não bastando somente selecionar e contratar, mas também tendo em vista o vetor de desempenho desses funcionários contratados e os ajudando a crescer junto com a empresa (APPEL; BITENCOURT, 2008).

A gestão de pessoas nas empresas, tem a necessidade de compreender as interação e relações entre pessoas, e nos ambientes de micro ou macro organizacionais deverão ser estabelecidos parâmetros de relações entre empresasempregados-parceiros, assim atentando para rápidas mudanças de cenários, acirrada competitividade (MARRAS, 2017).

RC: 84992

Disponível em: https://www.nucleodoconhecimento.com.br/administracao/grupo-millenium 
As organizações hoje veem as informações e o conhecimento como ativos estratégicos e devem investir em ações para evitar a perda desses ativos. Portanto, em muitas empresas, o gerenciamento de pessoas é considerado estratégico, pois proporciona a organização de pessoas e, portanto, as características necessárias para alcançar seus objetivos. Para isso, é preciso atrair os melhores profissionais, retê-los e motivá-los para o trabalho (MALAFAIA, 2017).

É muito importante que as empresas tentem reter bons profissionais, através de uma boa remuneração, porém ela não é suficiente para manter esse profissional na empresa é necessário que os gestores mantenham sua equipe sempre motivados e atuar constantemente para obter melhores resultados. É visando isso que a gestão de pessoas utiliza seus cinco pilares que são: Motivação, Processo de Comunicação, Trabalho em equipe, conhecimento e competência e treinamento e desenvolvimento.

\subsection{TEORIA DAS RELAÇÕES HUMANAS}

Foi realizado no ano de 1924 nos Estados Unidos uma pesquisa com a finalidade de obter a relação entre a produtividade e condições em que colaboradores se encontram em seu ambiente de trabalho a pesquisa foi conduzida Elton Mayo (DE OLIVEIRA, 2017).

A pesquisa adicionou à rotina de trabalho dos funcionários em estudo um tempo para descanso, informando que ficariam responsáveis por escolher quando seria o horário de descanso. Como resultado a pesquisa obteve um aumento na produção, melhoramento na relação interpessoal e ainda uma redução no desligamento dos funcionários (DIAZ; QUEIROZ; LOPEZ, 2018).

Nesta primeira fase foram necessárias a divisão de dois grupos de operárias, formadas por moças e seu respectivo supervisor, para verificar o nível de

RC: 84992

Disponível em: https://www.nucleodoconhecimento.com.br/administracao/grupo-millenium 
produtividade por dia, conforme as mudanças na iluminação. Vale ressaltar que este teste foi realizado apenas com um grupo de operárias, ficando assim o outro grupo com as mesmas condições de iluminação que já trabalhavam anteriormente (MARCELLO, 2012).

Destacaram-se nesta fase:

- Grupo de observação: Sob luz variável;

- Grupo de controle: Sob Luz Constante;

- Não encontraram correlação entre essas duas variáveis, mas detectaram o fator psicológico.

Destacaram-se nessa fase:

- capacidade produtiva;

- mudança de local de trabalho;

- modificou-se o sistema de pagamento;

- intervalo de cinco minutos de descanso;

- aumento no intervalo para 10 minutos;

- três intervalos de cinco minutos, quebra de ritmo de produção;

- período voltou-se a dois intervalos de dez minutos, em cada período, servindo-se um lanche leve;

- Grupo experimental passou em período menor;

- O grupo experimental o período de trabalho foi reduzido novamente contudo não houve mudança na produtividade;

- O período de trabalho foi aumentado para o inicial e a produtividade aumentou;

- Reduziu-se o os dias trabalhados como consequência a produtividade também aumentou.

RC: 84992

Disponível em: https://www.nucleodoconhecimento.com.br/administracao/grupo-millenium 
Criou-se o programa de entrevistas para saber como cada funcionário se sentia em seu respectivo trabalho, e o qual sua opinião em relação ao trabalho desempenhado. Foi muito bem aceita pelos funcionários pois era a primeira vez que tinham a oportunidade de ser ouvidos.

Essa fase teve como características:

- Objetivo tomar conhecimento acerca de como os colaboradores se sentiam com sua função e outros aspectos do trabalho;

- Realizou-se cerca 20.000 entrevistas.

O sistema de pagamento era baseado na produção do grupo. A quarta fase permitiu - estudo das relações entre a organização informal dos empregados e a organização formal da fábrica.

Essa experiência obteve os seguintes resultados: a produtividade não é determinada pelo desempenho físico e sim por como esse colaborador se sente em relação ao grupo. A competência e a eficiência são determinadas pela capacidade de se socializar de cada colaborador. Maior a coesão do grupo maior será essa relação no trabalho (RIBAS, 2015).

Os trabalhadores não reagem sozinhos e como indivíduos, mas como membros do grupo. Portanto, a equipe gerencial não pode lidar posteriormente, mas como membros dos grupos e estão sujeitos a influências sociais desses grupos (RIBAS, 2015).

A teoria da relação humana contrasta o comportamento social do empregado com o comportamento do tipo de máquina proposta pela teoria clássica. A teoria das relações humanas infere a motivação econômica não é prioridade (RIBAS, 2015).

RC: 84992

Disponível em: https://www.nucleodoconhecimento.com.br/administracao/grupo-millenium 
A teoria das relações humanas veio com necessidade de corrigir a desumanização do modelo da teoria clássica que focava apenas a estrutura organizacional.

\section{6 ÉTICA}

Segundo Mendes (2015) a ética enfatizada por correntes éticas diferentes tem em comum o fato de embasar a ética na moral humana levando em consideração seus princípios e valores. Os princípios éticos atuais estão alinhados com os conceitos de liberdade, compromisso, responsabilidade, equidade e justiça social. Os dilemas éticos estão ligados aos conceitos de certo ou errado, possuem consequências diretas ou indiretas na sociedade.

A corrupção é a expressão dos valores de uma dada cultura que justifica a exploração de uma pessoa por outra e que dá mais "inteligência e compreensão". Expõe a falência ética que garante a vida e se baseia na consciência de que toda ação pessoal se reflete no contexto social e no universo individual do indivíduo. $\mathrm{Na}$ prática da administração pública, a corrupção expõe um universo de valiosos investimentos, em que interesses privados prejudicam interesses públicos (GOMES, 2014).

Como a ética está intrinsecamente ligada à moral, principalmente no âmbito da administração pública. Para aumentar a eficiência na administração e liderança é necessário estar alinhado com os conceitos morais pautados em certos limites éticos não só pensando em aumentar recursos (MELLO, 2017).

\subsection{PRODUTIVIDADE}

A produtividade pode ser entendida como a aferição e contabilização de produtos ou bens oferecidos, correlacionando os meios com os recursos empregados e o resultado final obtido, levando em consideração pessoas, máquinas e outros indicadores de produtividade.

$\mathrm{RC}: 84992$

Disponível em: https://www.nucleodoconhecimento.com.br/administracao/grupo-millenium 
Geralmente este termo está relacionado com o rendimento de trabalho, sendo uma preocupação constante das empresas que buscam alternativas para aumentar a produtividade e reduzir os custos. Uma alternativa que vem sendo utilizada é o Lean Manufacturing, que pode ser entendido como:

Pensamento lean que é difundido no Sistema Toyota de Produção, que hoje está presente em diversas empresas, é muito necessário em razão do aumento dos concorrentes, que surgem no mercado todos os dias e a busca por uma excelência em manufatura é constante. Entre outros fatores que podem aumentar a produtividade, os colaboradores, como o autor afirmou anteriormente, têm um papel importante, desde os responsáveis pela gestão da empresa, gestão da produção, operadores e o setor de qualidade. Ranganathan (2011) afirma que "the ultimate goal of implementing lean production in an operation is to increase productivity, enhance quality, shorten lead times, reduce costs etc", dessa maneira as organizações conseguem alcançar suas metas desejadas.

Segundo Macedo (2012) a produtividade tem um papel de protagonista no crescimento de uma empresa, empresas sem uma alta produtividade não conseguirão ser competitivas e gradativamente perderão força, a eficiência dos processos produtivos não está somente relacionada com âmbito privado, mas atualmente uma preocupação de políticas públicas, preocupada com a competitividade mundial.

\subsection{FERRAMENTAS UTILIZADAS PARA SOLUÇÕES DE PROBLEMAS}

Para soluções de problemas e a busca por eficiência faz-se uso de um grande leque de ferramentas, que são usadas na rotina de uma empresa, para analisar dados, informações, discutir possíveis soluções e implementações e novas ideias para a solução de problemas. Gomes (2015), enfatiza que "a falta de cooperação,

RC: 84992

Disponível em: https://www.nucleodoconhecimento.com.br/administracao/grupo-millenium 
comunicação e são provocados nas alterações e mudanças nos processos e operações", pois em um ambiente empresarial muitas áreas estão relacionadas e é necessário a cooperação de todos para solucionar eventuais problemas, de forma a cooperar para o sucesso da mesma.

A seguir serão abordadas algumas ferramentas, como Brainstorming e $5 \mathrm{~W} 2 \mathrm{H}$, para buscar a solução e identificação de problemas.

\subsubsection{BRAINSTORMING}

Brainstorming ou simplesmente "tempestade de ideias" é quando há a reunião de pessoas, que livremente, sem críticas e interferências dão sugestões, todas essas ideias são bem-vindas, seguindo um princípio de quanto mais ideias, melhor de modo que possam ajudar na resolução de problemas de forma criativa e estimulando o grupo de pessoas a participarem (LUZ, 2016).

\subsubsection{W2H}

Essa ferramenta tem a função de auxiliar nas atividades que envolvem os planos de ação e determinam o tempo para ser executado. Fidelis (2017) afirma que "serve para aprovar que as informações básicas e mais fundamentais sejam declaradamente definidas e as ações e sugestões sejam minuciosas, porém simplificadas" facilitando assim sua implementação através de prazos, dos responsáveis, como as ações serão conduzidas, na Figura 1 pode-se visualizar as 7 palavras que originam o $5 \mathrm{~W} 2 \mathrm{H}$.

RC: 84992

Disponível em: https://www.nucleodoconhecimento.com.br/administracao/grupo-millenium 


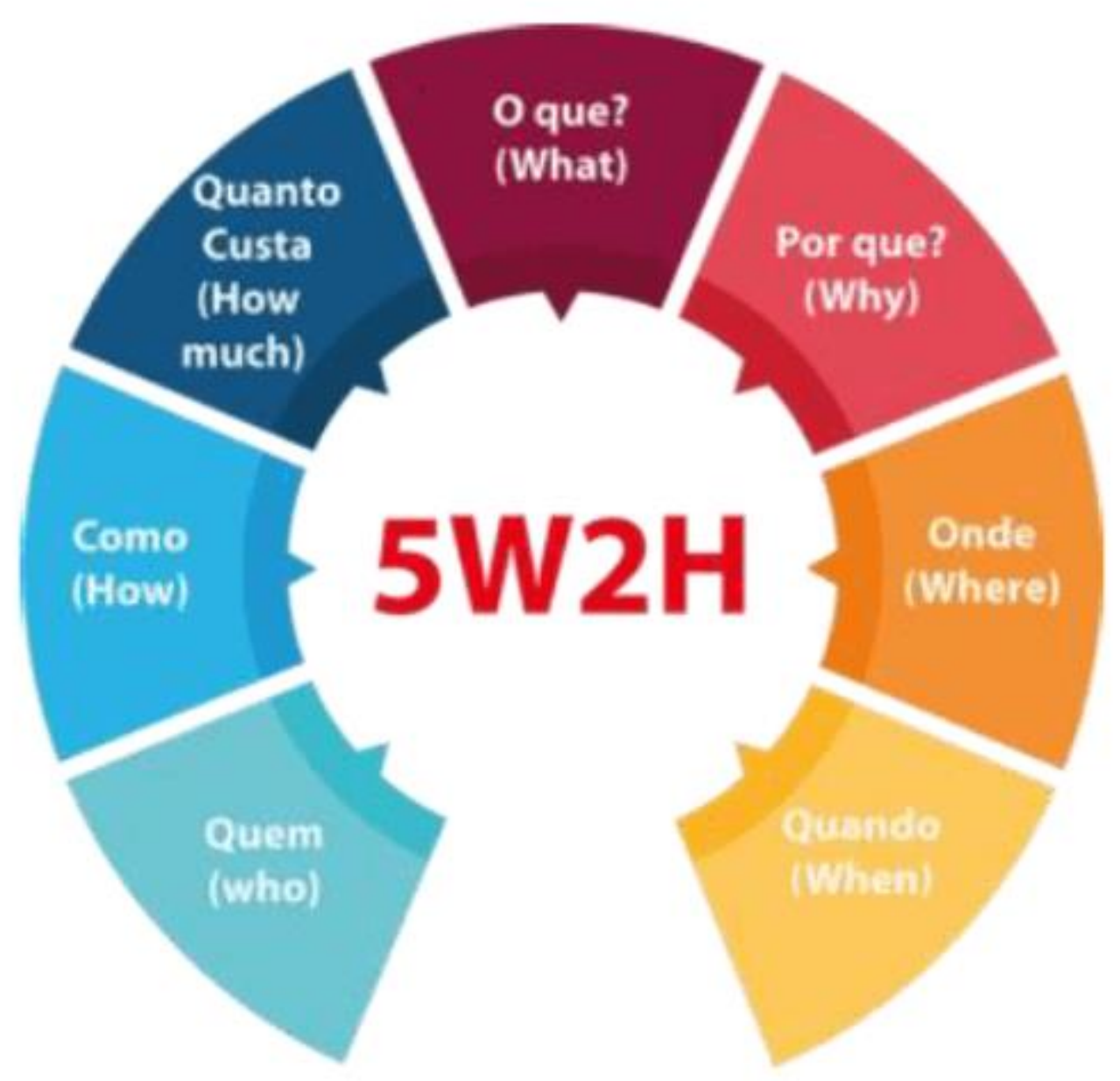

Fonte: Lean Blog (2016).

De acordo com os autores Fidelis (2017) e Pleitz (2013) uma explicação para essas palavras são:

- Whats: o que fazer para alcançar o objetivo;

- Who: o responsável pela execução de ações;

- Where: qual o lugar que será executada a ação;

RC: 84992

Disponível em: https://www.nucleodoconhecimento.com.br/administracao/grupo-millenium 
- When: o prazo de ação;

- Why: quais motivos que levaram a fazer tal ação.

\section{MATERIAIS E MÉTODOS}

Trata-se de uma revisão bibliográfica que utilizou as bases científicas de pesquisa de artigos indexados em periódicos nacionais no período de 2010 a 2021, bem como dissertações de Mestrado e teses de Doutorado, o trabalho ainda realizou um estudo de caso com a empresa Millenium acerca de seus programas de bonificação.

A metodologia usada para a construção do presente trabalho foi baseada em pesquisa bibliográfica, que Prestes (2008) afirma que é eficaz no solucionamento de um determinado problema deve-se empregar diversos tipos de dados.

Para a coleta de dados, em seu procedimento, priorizou-se por selecionar informações de caráter qualitativo, com o intuito de gerar um panorama de discussão. Os textos escolhidos sob critérios de data de publicação, possibilitando dessa forma uma reflexão crítica para os leitores com intuito de demarcar ideias principais dos textos pesquisados.

\subsection{CARACTERIZAÇÃO DA EMPRESA}

A empresa foi fundada em Manaus em 2016 e possui como atividade principal atividades de vigilância e segurança privada, possuindo como Capital Social quatrocentos mil reais (MILLENIUM, 2021).

A empresa possui como a excelência na prestação de serviços de serviços de segurança, a empresa tem como visão. Ser reconhecida e tornar se referência em nosso segmento, com atitudes inovadoras e mudando o conceito de prestação de serviços nas áreas em que atuam (MILLENIUM, 2021).

$\mathrm{RC}: 84992$

Disponível em: https://www.nucleodoconhecimento.com.br/administracao/grupo-millenium 


\section{RESULTADOS E DISCUSSÕES}

Para os resultados foram selecionados 5 artigos discutindo sobre o tema proposto, foram utilizados os seguintes autores: Lacombe, Budach, de Oliveira, Faleiro, Santos, Borges e Machado.

Para Lacombe (2017) os recursos humanos eram bem abundantes e comumente eram encontrados um grande número de trabalhadores dispostos a trabalhar nas portas de fábricas ou em canteiros de obras em espera para ingressarem em uma atividade laboral. Nas décadas anteriores o trabalho tinha uma maior dependência de trabalhadores braçais, contudo com a revolução industrial essa mão de obra ficou cada vez mais escassa, com a globalização e o aumento da concorrência as empresas tiveram que buscar pessoas mais qualificadas e com um nível cultural maior.

Budach (2016) complementa com a busca por profissionais cada vez mais capacitados, houve também a geração de uma nova demanda, os profissionais mais capacitados encontram-se não só buscando por salários melhores, mas também por objetivos de vida. Dessa forma as empresas a fim de manter seus melhores profissionais deve criar maneiras para valorizar seus colaboradores, para que possam se manterem motivados e focados em suas funções gerando por sua vez um aumento de produtividade e lucro para empresa.

As empresas devem bonificar seus funcionários não apenas com um bônus de salário, e sim gerar benefícios que possam atender as necessidade e expectativas de seus colaboradores, fornecendo crescimento profissional e pessoas, reconhecimento de seu valor para empresa e promover um ambiente em que os funcionários possam se sentir acolhidos (DE OLIVEIRA, 2017).

RC: 84992

Disponível em: https://www.nucleodoconhecimento.com.br/administracao/grupo-millenium 
Conforme Faleiro (2020) o benefício pode ser entendido como a junção de programas ofertados pela empresa ou ainda planos oferecidos para complementação do salário de seu colaborador. Muitos profissionais priorizam empresas que oferecem benefícios. Esses benefícios podem ser remunerados ou não. Esses benefícios podem ser divididos em benefícios compulsórios e em benefícios espontâneos.

A empresa concede os benefícios compulsórios quando existe uma lei que obriga as empresas a fornecerem esse benefício os benefícios compulsórios mais comuns são férias remuneradas, licença maternidade e $13^{\circ}$ salário. Já os benefícios espontâneos são os benéficos que a organização promove a seus funcionários sem que haja uma obrigação para tal, esse tipo de benefício tem por intuito atender as necessidades dos funcionários e aumentar a produtividade (SANTOS; BORGES; MACHADO, 2018).

Profissionais que possuem um desempenho acima da média e não recebem a devida atenção por parte da empresa tendem a buscar outras empresas, aumentando dessa forma a rotatividade dentro da empresa. Algumas empresas para diminuir o índice de rotatividade criam um sistema de bonificação para valorizar os profissionais que mais se empenham, como ocorre no Magazine Luiza (SANTOS; BORGES; MACHADO, 2018).

\subsection{PLANEJAMENTO DE AÇÕES}

O planejamento de ações tem como objetivo direcionar e organizar as propostas de soluções, a fim de alcançar os objetivos da organização. O Grupo Millenium Segurança Patrimonial não possui um sistema de bonificação para os colaboradores, com isso foi proposto seis (6) ações descritas no Quadro 1 a seguir, para sanar este problema principal.

RC: 84992

Disponível em: https://www.nucleodoconhecimento.com.br/administracao/grupo-millenium 
Quadro 1: Sugestões de Políticas Motivacionais

\begin{tabular}{|c|c|c|}
\hline Programa & Descrição & Bonificação \\
\hline $\begin{array}{l}\text { Recrutamento interno } \\
\text { de colaboradores para } \\
\text { preenchimento de } \\
\text { vaga }\end{array}$ & $\begin{array}{l}\text { Prioriza os colaboradores para } \\
\text { preencher novas vagas na } \\
\text { empresa. }\end{array}$ & $\begin{array}{l}\text { Incentivo a um plano de } \\
\text { carreira e permanência na } \\
\text { empresa. }\end{array}$ \\
\hline $\begin{array}{l}\text { Integração e } \\
\text { acolhimento de novos } \\
\text { membros }\end{array}$ & $\begin{array}{l}\text { O acolhimento de novos } \\
\text { membros é de vital } \\
\text { importância para a promoção } \\
\text { da cultura da empresa. }\end{array}$ & $\begin{array}{l}\text { O colaborador ao ingressar } \\
\text { na empresa possui o } \\
\text { sentimento de } \\
\text { pertencimento, absorvendo } \\
\text { melhor a cultura da } \\
\text { empresa. }\end{array}$ \\
\hline $\begin{array}{l}\text { Canais de sugestões } \\
\text { e desenvolvimento }\end{array}$ & $\begin{array}{l}\text { A empresa deve incentivar } \\
\text { aos colaboradores a fornecer } \\
\text { sugestões para } \\
\text { melhoramento da empresa }\end{array}$ & $\begin{array}{l}\text { Valorização das ideias do } \\
\text { colaborador. }\end{array}$ \\
\hline Conselho colaborativo & $\begin{array}{l}\text { Colaboradores destaques } \\
\text { podem tomar decisões juntos } \\
\text { com os gerentes de cada } \\
\text { unidade da empresa. }\end{array}$ & $\begin{array}{l}\text { Oportunidade de participar } \\
\text { de decisões importantes da } \\
\text { empresa. }\end{array}$ \\
\hline $\begin{array}{l}\text { Reunião entre todos } \\
\text { os colaboradores }\end{array}$ & $\begin{array}{l}\text { Reunião todas onde os } \\
\text { colaboradores têm a } \\
\text { oportunidade de expressar-se } \\
\text { acerca do dia a dia na } \\
\text { empresa. }\end{array}$ & $\begin{array}{l}\text { Promove um ambiente } \\
\text { interativo e descontraído. }\end{array}$ \\
\hline Funcionário padrão & $\begin{array}{l}\text { Oferece uma bonificação para } \\
\text { funcionários que atingirem as } \\
\text { metas determinadas pela }\end{array}$ & $\begin{array}{l}\text { Bonificação } \\
\text { reconhecimento pelo bom } \\
\text { serviço prestado }\end{array}$ \\
\hline
\end{tabular}

RC: 84992

Disponível em: https://www.nucleodoconhecimento.com.br/administracao/grupo-millenium 


empresa, além do
reconhecimento pelo bom
serviço prestado.

Fonte: Grupo Millenium 2021

A empresa Millenium não possui um sistema de bonificação, construiu-se o quadro acima e validou-se com um comitê de colaboradores a necessidade de a aplicação de ferramentas para a identificação das políticas organizacionais que poderiam contribuir com uma maior motivação das equipes funcionais.

Para identificarem-se quais políticas motivacionais poderiam ser introduzidas no processo utilizaram-se as ferramentas Brainstorming a fim de apontar quais políticas que fossem compatíveis com a capacidade de investimento da organização sem perder de vista o foco que norteia este estudo e responder a questão problema: Como a introdução de políticas motivacionais de bonificação pode contribuir com o aumento da produtividade dos colaboradores?

\subsubsection{PREFERÊNCIA RECRUTAMENTO INTERNO PARA VAGAS}

O recrutamento interno não era uma prática comum na organização e mesmo com colaboradores habilitados para vaga dificilmente eram disponibilizadas para os funcionários ativos, uma das demandas da equipe era participar do processo seletivo visto que, o processo de integração se torna mais rápido visto que os candidatos internos e conhecem as políticas, valores, missão, ou seja, os fatores fundamentais para proporcionar o atendimento de metas organizacionais. A seguir no quadro 2 se descreve o processo de recrutamento interno.

RC: 84992

Disponível em: https://www.nucleodoconhecimento.com.br/administracao/grupo-millenium 
Quadro 2 - Recrutamento Interno Para Preenchimento De Vagas

\section{RECRUTAMENTO INTERNO PARA PREENCHIMENTO DE NOVAS VAGAS \\ O QUE? Prioriza os colaboradores para preencher novas vagas na empresa. \\ POR Incentivo a um plano de carreira e permanência na empresa. \\ QUÊ? \\ ONDE? Departamento de Recrutamento e Seleção da Empresa \\ QUANDO? Necessidade de preenchimento de novas vagas \\ QUEM? Funcionários ativos da organização \\ COMO? Preparação dos colaboradores através de desenvolvimento e treinamento visando tornar as equipes multifuncionais e maximizar o aproveitamento interno para novas oportunidades dentro da organização.}

QUANTO? R $\$ 2000,00$ por mês - verba para treinamento em novas habilidades.

O processo de recrutamento interno visa a preparar um plano de carreira para que todos os colaboradores da organização possam se desenvolver e ter objetivos claros de desenvolvimento profissional a fim de estar preparados para vagas quando as mesmas apareçam. Por ser uma empresa de prestação de serviços de segurança muito bem-conceituada no mercado de Manaus novos contratos podem surgir a qualquer momento e a empresa precisa ter mão de obra habilitada para eventualmente aceitar novos contratos sem perder o padrão de nível de serviço que é prestado aos clientes atuais.

\subsubsection{INTEGRAÇÃO E ACOLHIMENTO DE NOVOS MEMBROS}

A empresa também não tinha a prática de fazer um processo estruturado de integração aos novos colaboradores, visto que normalmente seus processos

RC: 84992

Disponível em: https://www.nucleodoconhecimento.com.br/administracao/grupo-millenium 
seletivos buscavam profissionais com experiência anterior na função, porém quando se trata de serviço os padrões podem variar de empresa para empresa e o processo se mostrava ineficaz devido aos padrões de serviço executados pela empresa estudada são diferentes de seus principais concorrentes e com isso os colaboradores ora contratados traziam vícios operacionais de outras organizações que diferem das práticas da empresa estudada.

Sendo assim justifica-se a implementação do programa de integração conforme descrito no quadro 3.

Quadro 3 - Integração E Acolhimento De Novos Colaboradores

\section{ACOLHIMENTO DE NOVOS COLABORADORES}

O QUE? O acolhimento de novos membros é de vital importância para a promoção da cultura da empresa.

POR $\quad$ O colaborador ao ingressar na empresa possui o sentimento de QUÊ? pertencimento, absorvendo melhor a cultura da empresa.

ONDE? Departamento de recrutamento e seleção

QUANDO? Durante o processo de integração na organização

QUEM? Gestor da vaga preenchida e recursos humanos

COMO? Programa de integração de novos colaboradores onde serão apresentadas as políticas organizacionais e atribuições do cargo preenchido

QUANTO? R $\$ 500,00$ por vaga preenchida no processo de seleção

Fonte: Grupo Millenium. 2021.

Construiu-se a partir dos estudos o sentimento de que é de fundamental importância o processo de integração de novos colaboradores, este fato se justifica pela necessidade de aculturar o novo colaborador as práticas e valores da organização

$\mathrm{RC}: 84992$

Disponível em: https://www.nucleodoconhecimento.com.br/administracao/grupo-millenium 
para evitar que o novo colaborador traga vícios adquiridos em outras organizações de mesmo seguimento que não sejam práticas utilizadas pela empresa estudada.

\subsubsection{CANAIS DE SUGESTÕES E DESENVOLVIMENTO}

Outra necessidade identificada no estudo se refere à se instituir de um canal de comunicação oficial para elaboração de propostas de melhorias aos processos organizacionais visto que o processo de comunicação é complicado pois $90 \%$ da equipe de colaboradores prestam serviço externo nas empresas contratantes. Porém mesmo com as dificuldades de comunicação é necessário que se estabeleça um padrão de serviço e o processo de melhoria contínua necessário a se programar novas práticas de serviço e manter os clientes satisfeitos: No quadro 4 detalha-se a introdução do processo dos canais de sugestões e desenvolvimento.

Quadro 4 - Canais De Sugestões E Desenvolvimento

\section{CANAIS DE SUGESTÕES E DESENVOLVIMENTO}

O QUE? A empresa deve incentivar aos colaboradores a fornecer sugestões para o do nível de serviço oferecido pela empresa

POR Valorização das ideias do colaborador e padronização continua do QUÊ? nível de serviço oferecido aos clientes

ONDE? Gerência operacional corporativa

QUANDO? Processo de desenvolvimento de melhoria contínua do nível de serviço oferecido.

QUEM? Colaboradores e gerência operacional.

COMO? Por meio de sugestões apresentadas aos supervisores dos contratos por meio de preenchimento de formulário específico.

QUANTO? $R \$ 1000,00$ - Relativo ao tempo destinado à análise das sugestões e avaliação da efetividade da proposta e introdução padronizada para todos os contratos ativos

RC: 84992

Disponível em: https://www.nucleodoconhecimento.com.br/administracao/grupo-millenium 
Fonte: Grupo Millenium. 2021.

Verifica-se que o Nível de serviço oferecido é fundamental para manutenção dos contratos ativos e captação de novos clientes sem esta uma potente ferramenta de captação de novos contratos. Sendo assim ouvir as demandas dos contratantes do serviço e introduzi-las é de fundamental importância e mostra-se fundamental a introdução de um efetivo e robusto canal de comunicação entre o nível estratégico, tático e operacional da organização estudada.

\subsubsection{CONSELHO COLABORATIVO}

Averiguou-se que após uma maior integração, mesmo que não estruturada de comunicação entre as equipes funcionais e a equipe tática e estratégica da organização proporcionou um plano de ações que pudesse solucionar a questão motivacional dos colaboradores. Para caracterização da importância do capital intelectual da organização a empresa propôs a instituição de um conselho colaborativo constituído por representantes dos colaboradores para reuniões mensais com as equipes gerência de operações: No quadro 5 detalha-se o procedimento das etapas de construção do conselho consultivo da empresa estudada.

Quadro 5 (5w2h) - Conselho Colaborativo

\section{CONSELHO COLABORATIVO}

\begin{tabular}{|c|c|}
\hline O QUE? & $\begin{array}{l}\text { A equipe consultiva participa ativamente das decisões corporativas } \\
\text { destinadas aos colaboradores em conjunto com os gerentes de cada } \\
\text { contrato da empresa. }\end{array}$ \\
\hline $\begin{array}{l}\text { POR } \\
\text { QUÊ? }\end{array}$ & $\begin{array}{l}\text { Oportunidade de participação de decisões importantes da empresa } \\
\text { relativo ao futuro dos colaboradores }\end{array}$ \\
\hline ONDE? & da diretoria \\
\hline
\end{tabular}

RC: 84992

Disponível em: https://www.nucleodoconhecimento.com.br/administracao/grupo-millenium 


\section{QUANDO? Frequência mensal \\ QUEM? Representantes do conselho colaborativo e gestores da empresa \\ COMO? Café da manhã mensal entre as equipes visando discussão das estratégias e também integrar as equipes como momentos de descontração e participação, além do que pode-se desenvolver maior confiança entre as equipes funcionais da organização.}

QUANTO? $\mathrm{R} \$ 1.500,00$ - investimento mensal

Fonte: Grupo Millenium. 2021.

Acredita-se que a introdução do conselho consultivo irá trazer às equipes funcionais o sentimento de participação e de valorização aos colaboradores que podem se motivar com ações desta natureza. A direção da organização tem plena confiança que esta ação interventiva irá proporcionar excelentes ganhos operacionais bem como motivacionais.

\subsubsection{REUNIÃO ENTRE TODOS OS COLABORADORES}

Percebe-se que a comunicação com os colaboradores é fundamental para este tipo de negócio, porém devido a característica do serviço prestado é impossível reunir todos os colaboradores ao mesmo tempo para reuniões coletivas. Sendo assim os gerentes de cada contrato tem a missão de fazer estas reuniões em pequenos grupos dentro das empresas contratantes.

Quadro 6 (5w2h) - Reunião Entre Todos Os Colaboradores

\begin{tabular}{l} 
REUNIÃO ENTRE TODOS OS COLABORADORES \\
\begin{tabular}{|l|l|}
\hline O QUE? & $\begin{array}{l}\text { Reunião todas onde os colaboradores têm a oportunidade de } \\
\text { expressar-se acerca do dia a dia na empresa. }\end{array}$ \\
\hline POR & Promover um ambiente interativo e descontraído.
\end{tabular} \\
\hline
\end{tabular}

RC: 84992

Disponível em: https://www.nucleodoconhecimento.com.br/administracao/grupo-millenium 


\begin{tabular}{|l|l|}
\hline QUÊ? & \\
\hline ONDE? & Dentro das empresas contratantes \\
\hline QUANDO? & Semanal e mensal \\
\hline QUEM? & Gerente do contrato e colaboradores \\
\hline COMO? & $\begin{array}{l}\text { Elaboração de pautas para debater como os colaboradores de cada } \\
\text { contrato }\end{array}$ \\
\hline QUANTO? & $\mathrm{R} \$ 800,00$ por contrato \\
\hline
\end{tabular}

Fonte: Grupo Millenium. 2021.

A realização destas reuniões de objetivo de proporcionar uma comunicação transversal em os níveis Estratégico, Tático e Operacional da organização visando manter as equipes operacionais com o sentimento de participação ativa das oportunidades, fortalezas, ameaças e fraquezas da organização proporcionando as equipes motivação necessária ativa para realização no maior nível de serviço aos objetivos do contrato que está inserida.

\subsubsection{FUNCIONÁRIO PADRÃO}

Constata-se que devido às ações apresentadas neste estudo à necessidade precípua de identificar os funcionários em destaque e premiá-los. Sendo assim decidiu-se introduzir a avaliação 360 graus para apurar através de indicadores de resultados os vencedores de cada semestre além de designar uma verba semestral para o evento. No quadro 7 apresenta-se a metodologia para verificação do funcionário padrão semestral.

Quadro 7 - Funcionário Padrão

\section{FUNCIONÁRIO PADRÃO}

O QUE? Oferecer uma bonificação para funcionários que atingirem as metas

RC: 84992

Disponível em: https://www.nucleodoconhecimento.com.br/administracao/grupo-millenium 
determinadas pela empresa, além do reconhecimento pelo bom serviço prestado.

POR $\quad$ Bonificação e reconhecimento pelo bom serviço prestado

QUÊ?

ONDE? Gerência Geral de operações / direção da empresa

QUANDO? Semestral

QUEM? Colaboradores com melhores resultados de desempenho

COMO? Avaliação 360 graus

QUANTO? $R \$ 3000,00$ semestral

Fonte: Grupo Millenium. 2021.

Ressalta-se que a introdução de uma bonificação para os colaboradores que obtenham melhores resultados na avaliação 360 graus institucionaliza uma disputa saudável por resultados e face a característica deste tipo de avaliação é muito difícil não se escolher os melhores na apuração dos resultados. A direção da organização determinará premiações diferenciadas de acordo com a verba estipulada para cada evento de divulgação dos funcionários padrão do semestre.

\section{CONCLUSÕES}

A partir da análise realizada pelos autores evidencia-se pontos preponderantes que foram indispensáveis para o crescimento da empresa, observando os resultados pode-se elencar os tais fatores, destacando-se o emprego da valorização dos funcionários mais antigos na empresa, o incentivo que a empresa promove a seus colaboradores a se qualificarem criando dessa forma um plano de carreira, priorização dos colaboradores a ocupar novas vagas e a valorização dos profissionais mais empenhados.

RC: 84992

Disponível em: https://www.nucleodoconhecimento.com.br/administracao/grupo-millenium 
Os fatores que levaram ao seu crescimento são evidenciados através de diversos investimentos em um sistema de bonificação que preza a valorização, sentimento de pertencimento e um ambiente democrático onde os colaboradores podem participar das decisões da empresa.

A proposta de um sistema de bonificação tem por intuito promover o crescimento da empresa prezando a valorização, sentimento de pertencimento e um ambiente democrático onde os colaboradores podem participar das decisões da empresa.

O presente trabalho buscou contribuir para futuras pesquisas acerca do tema adotado e como proposta para ideias vindouras, as quais poderão ser aprofundadas.

\section{REFERÊNCIAS}

BIANCHI, E. M. P. G. et al. Atuação do líder na gestão estratégica de pessoas: Reflexões, lacunas e oportunidades. RAC-Revista de Administração Contemporânea, v. 21, n. 1, p. 41-61, 2017.

BUDACH, K. E. Análise da variabilidade da produtividade mediante implantação de sistema de bonificação. 2016. Trabalho de Conclusão de Curso. Universidade Tecnológica Federal do Paraná.

CHIAVENATO, I. Gestão de pessoas: o novo papel dos recursos humanos nas organizações. 4 ed. Barueri, SP: Manole, 2014.b

CRUZ, S. et al. Gestão estratégica, liderança, e cultura nas organizações do terceiro setor. Empreendedorismo social em Portugal, 2014.

DALL'OGLIO, A. et al. A LIDERANÇA E SUA CAPACIDADE DE GERAÇÃO DE RESULTADOS. 2014.

RC: 84992

Disponível em: https://www.nucleodoconhecimento.com.br/administracao/grupo-millenium 
DE OLIVEIRA, A. S. Satisfação dos funcionários com os benefícios oferecidos pelas empresas. 2017.

DIAS, M. A. M. J. et al. Estilos de liderança e desempenho de equipes no setor público. READ-Revista Eletrônica de Administração, v. 21, n. 1, p. 200-221, 2015.

FALEIRO, L. I. Análise dos benefícios ofertados aos colaboradores de um abatedouro localizado no Vale do Taquari. 2020.

FERNANDES, A. de L. 0 processo da liderança em organizações que aderiram ao modelo de excelência em gestão: um estudo em duas empresas paraibanas. 2016.

FIDELIS, R. S. Melhoria e produtividade em uma mineração de calcário. Ponta Grossa, 2017. Originalmente apresentado como Monografia, para a obtenção de título de especialista em Engenharia de Produção, Universidade Tecnológica Federal do Paraná, 2017.

GARCIA, D. B. Os diferentes tipos de Liderança e sua influência no clima organizacional. Data da publicação, v. 13, 2015.

GIL, A. C. Como elaborar projeto de pesquisa. 4. ed. São Paulo: Atlas, 2002.

GOMES, N. F. Ética na administração pública: desafios e possibilidades. Revista de Administração Publica-RAP, 2014, 48.4: 1029-1050.

GOMES, R. L. Controle de Processos Produtivos em uma Indústria de Alimentos. Medianeira, 2015. Originalmente apresentado como Monografia, para título de Bacharel em Engenharia de Produção, Universidade Tecnológica Federal do Paraná. 
HOFFMANN, E. et al. Análise Dos Indicadores Econômico-Financeiros Das Empresas Varejistas Magazine Luiza e Via Varejo. Revista de Administração e Negócios da Amazônia, v. 9, n. 3, p. 60-82, 2017.

LACOMBE, F. J. M. Recursos humanos. Saraiva Educação SA, 2017.

LEAN BLOG. As ferramentas de análise 5W2H e GUT. 2016. Disponível em: < https://lean.blog.br/5w2h-e-gut/>. Acesso em: 09 de abr. de 2021.

LUZ, D. V. D. Desenvolvimento de produtos: um estudo de caso. Lajeado, 2016. Originalmente apresentado como trabalho de conclusão de curso, Centro Universitário Univates, 2016.

MALAFAIA, G. S. Gestão estratégica de pessoas em ambientes multigeracionais., v. 18, 2017.

MARRAS, J. P. Gestão estratégica de pessoas. Saraiva, 2017

MELLO, M. A. A ética nas funções de Estado. Revista Interdisciplinar de Direito, 2017, 12.1

MENDES, A. V. C. et al. Gestão da ética: a experiência da administração pública brasileira. Administração Pública e Gestão Social, 2015, 7.1: 2-8.

MILLENIUM. Grupo Millenium. 2021.https://grupomilleniumseg.com.br/site/. Acesso em: 09 de abr. de 2021.

PEREIRA, A. L. A liderança como um fator de diferencial competitivo. Negócios em Projeção, v. 5, n. 1, 2014. 
PRODANOV, C. C.; FREITAS, E. C. de. Metodologia do trabalho científico: métodos e técnicas da pesquisa e do trabalho acadêmico. 2. ed. Novo Hamburgo: Feevale, 2013.

RAMOS, F. P. Liderança e inteligência emocional no contexto da gestão de pessoas: um estudo de caso através do filme'Mestre dos mares'. Revista de Ciências Gerenciais, v. 14, n. 20, 2015.

SANTOS, D. F. B. et al. Medidas para redução do absenteísmo nas empresas. QUALIA: a ciência em movimento, v. 4, n. 1, p. 77-91, 2018.

SILVA. A. K. F. Análise de práticas de gestão de pessoas na construção civil. 2018. Originalmente apresentado como como projeto de graduação ao curso de engenharia civil, Universidade Federal Rio de Janeiro, 2018. 78f.

Enviado: Abril, 2021.

Aprovado: Maio, 2021. 